\title{
Multicentre evaluation of an emergency department asthma care pathway for adults
}

\author{
M. Diane Lougheed, MD, MSc; ${ }^{* \dagger}$ Jennifer Olajos-Clow, RN(EC), MSc, CAE; ${ }^{* \dagger}$ Kim Szpiro, RN, MSc; ${ }^{* \dagger}$ \\ Patricia Moyse, RN, CAE; ${ }^{* \dagger}$ Brianna Julien, RN, BScN, BAH, BSc; ${ }^{* \dagger}$ Miao Wang, MD, MSc; ${ }^{*}$ \\ Andrew G. Day, MSc; ${ }^{*}$ Ontario Respiratory Outcomes Research Network
}

\begin{abstract}
Objective: We sought to determine whether a standardized emergency department (ED) asthma care pathway (ACP) for adults would be accepted by ED staff, improve adherence to Canadian ED asthma management guidelines and improve patient outcomes.

Methods: Ten Ontario hospital EDs (5 intervention, 5 control) participated in a 5-month pre-post intervention study. Emergency department management, admissions, repeat ED visits and ED length of stay were compared between sites and by ACP use versus nonuse at intervention sites.

Results: The ACP was used in 101 of 383 visits (26.4\%) at 5 intervention sites. Use of the ACP varied significantly between sites, ranging from $6 \%$ to $60 \%(p<0.001)$. When compared with control sites, there were significant increases in the use of metered dose inhalers (MDIs), inhaled steroids, referrals, documentation of teaching, patient recollection of teaching (all with a $p<0.001$ ) and oxygen $(p=0.001)$. Use of peak expiratory flow rate (PEFR) measurements decreased in both intervention and control sites. Increased PEFR documentation and systemic steroid use in the ED and on discharge were only found in patients who were on the ACP at intervention sites. Admissions increased from $3.9 \%$ to $9.4 \%$ at intervention sites in contrast to control sites, where they remained fairly stable $(p=0.016)$, but did not differ by ACP use. The length of stay for discharged patients increased by a mean of 16 minutes for ACP patients at intervention sites $(p=0.002)$. There were no statistically significant differences in repeat ED visits. Conclusion: Adoption of a standardized ED ACP for adults is highly variable. Despite modest uptake, which averaged $26 \%$, beneficial changes in specific aspects of asthma care delivery were found, notably in referrals and recollection of teaching done during the ED visit, without a substantial increase in ED length of stay. These changes may lead to improvements in
\end{abstract}

outcomes, such as reduced relapse rates, which this study was not designed or powered to detect. Provincial and national implementation strategies that address barriers to clinical pathway adoption are warranted and have the potential to improve adherence to guidelines and outcomes for asthma patients.

Keywords: asthma, care map, clinical pathway, emergency department, guidelines, knowledge translation

\section{RÉSUMÉ}

Objectif : Nous avons voulu vérifier si un plan clinique standardisé pour le traitement de l'asthme chez l'adulte serait accepté par le personnel des urgences et s'il allait promouvoir l'observance des lignes directrices canadiennes pour la prise en charge de l'asthme aux urgences et améliorer le pronostic des patients.

Méthode : Dix services d'urgence d'hôpitaux en Ontario (5 appliquant l'intervention et 5 témoins) ont participé à cette étude pré- et post-intervention d'une durée de 5 mois. Nous avons comparé la prise en charge, les admissions, les visites multiples et la durée du séjour aux urgences entre les différents services, selon qu'ils appliquaient ou non le plan clinique.

Résultats : Cinq services d'urgence assignés au groupe appliquant I'intervention ont effectivement utilisé le plan clinique lors de 101 consultations (26,4\%) sur 383. L'utilisation du plan clinique a varié significativement d'un service d'urgence à l'autre, soit de 6 à $60 \%(p<0,001)$. Comparativement aux services d'urgence témoins, on a noté une augmentation significative de l'utilisation des aérosols-doseurs et des corticostéroïdes par inhalation, des demandes de consultation, de l'enseignement au patient (documenté), du rappel des notions enseignées avec le patient (tous, $p<0,001$ ) et du recours à l'oxygène $(p=0,001)$. L'utilisation des mesures

From the ${ }^{*}$ Clinical Research Centre, Kingston General Hospital, Kingston, Ont., and the †Department of Medicine, Queen's University, Kingston, Ont.

The revised adult asthma care pathway tools and materials are available from the Ontario Lung Association website (www.on.lung.ca/Health -Care-Professionals/EDACP/index.php).

Submitted Feb. 8, 2008; Revised Oct. 21, 2008; Accepted Nov. 28, 2008

This article has been peer reviewed.

CJEM 2009;11(3):215-29 
du débit expiratoire de pointe a diminué, tant dans les services d'urgence qui appliquaient le plan clinique que dans les services d'urgence témoins. Pendant le séjour aux urgences et au moment du congé, le recours au débit expiratoire de pointe documenté et aux corticostéroïdes systémiques n'a augmenté que chez les patients admis aux services d'urgence qui appliquaient le plan clinique. Les admissions sont passées de 3,9 à 9,4\% dans les services d'urgence qui appliquaient le plan clinique, tandis qu'elles sont restées relativement stables $(p=0,016)$ dans les services d'urgence témoins, mais ces taux n'ont pas différé en fonction de l'application du plan clinique. Chez les patients qui recevaient leur congé, la durée du séjour augmentait en moyenne de 16 minutes pour les patients soumis au plan clinique dans les urgences qui l'appliquaient $(p=0,002)$. On n'a noté aucune différence statistiquement significative pour ce qui est des visites multiples aux urgences.
Conclusion : L'adoption d'un plan clinique standardisé pour le traitement de l'asthme chez l'adulte qui consulte aux urgences est très variable. Malgré un degré d'adoption modeste, soit en moyenne $26 \%$, nous avons observé des améliorations sous plusieurs aspects de la prestation des soins pour I'asthme, notamment au chapitre des demandes de consultation et du rappel des notions enseignées durant la consultation aux urgences, ces mesures $n^{\prime}$ ayant toutefois pas prolongé substantiellement le séjour. Ces changements pourraient contribuer à améliorer le pronostic, en réduisant les taux de rechute, par exemple; précisons que le modèle de l'étude et sa puissance statistique ne permettaient pas de mesurer ce paramètre. Des stratégies d'application provinciales et nationales s'imposent pour tenter d'éliminer les obstacles à l'adoption d'un plan clinique et pour améliorer l'observance des lignes directrices et le pronostic des patients asthmatiques.

\section{INTRODUCTION}

Approximately $40 \%$ of Canadians with asthma are admitted to hospital, attend an emergency department (ED) or have an urgent care visit for asthma each year., ${ }^{1,2}$ Variations between and within provinces in rates of hospital admissions and ED visits for asthma in children and in adults $^{3-6}$ have been documented. These variations raise concerns regarding the quality of and access to asthma care in communities and EDs. The Ontario Asthma Regional Variation (OARV) Study found that rates of hospital admission were primarily influenced by variation in admission percentages rather than rates of ED visits. ${ }^{6}$ There are significant regional variations in ED practice patterns and discrepancies between evidence-based guidelines and current practices. ${ }^{7-9}$ In Ontario, the most notable care gaps are underuse of objective measures of airflow rates and systemic steroids both in the ED and on discharge, and extremely low referral rates. ${ }^{9}$

It is increasingly clear that adoption of guidelines hinges on successful knowledge translation and implementation initiatives. ${ }^{10,11}$ Clinical pathways can be effective means of supporting best practice for a variety of conditions and settings, including asthma. Single-centre studies have revealed variable improvements in patient outcomes, including bronchodilator use, ${ }^{12}$ measurement of peak expiratory flow rate (PEFR), ${ }^{13}$ systemic steroid use $^{13,14}$ and admissions. ${ }^{14}$ A recent Ontario study of pediatric asthma management strategies reported that preprinted orders used in 26 of 152 EDs were associated with a $32 \%$ relative risk reduction of repeat ED visits within 72 hours, ${ }^{15}$ presumably by embedding evidencebased medicine into clinical practice.
The Ontario Ministry of Health and Long-Term Care, as part of the Asthma Plan of Action, ${ }^{16}$ recently funded the Ontario Hospital Association to manage the development and pilot testing of a standardized ED asthma clinical pathway and care map for adult asthma. Its purpose was to provide an operational version of the Canadian Asthma Consensus Guidelines and the Canadian Association of Emergency Physicians (CAEP)/Canadian Thoracic Society (CTS) guidelines for the management of asthma in the ED, ${ }^{17-19}$ to thus encourage adherence to best practice in a manner suitable for province-wide implementation. The asthma care pathway (ACP) was developed by an Expert Content Working Group (Box 1) and was designed to address 6 key objectives (Box 2).

A study was designed by the Ontario Respiratory Outcomes Research Network with input from the ED ACP Steering Committee to evaluate the uptake of the ED ACP and its impact on asthma care and patient outcomes. It was hypothesized that implementation of a multidisciplinary adult ED ACP would increase adherence to ED management guidelines, increase referrals to specialized asthma services following ED visits and improve patient outcomes. The primary outcomes of interest were the proportion of eligible asthma patients who were managed on the ACP and the proportion who received systemic steroids in the ED. Secondary outcomes included other ED management strategies prompted by the ACP, patient recollection of teaching and administrative outcomes including admission percentage, length of stay in the ED and repeat ED visit percentage. 


\section{METHODS}

\section{Study design}

Ten Ontario EDs participated in a nonrandomized, controlled, pre-post intervention study. To achieve a matched sample that included academic and community hospitals, urban and rural locations, and hospitals from various-sized communities across the province, 8 OARV study sites and 2 additional small rural sites were invited to participate using a previously described sampling approach. ${ }^{6}$ Proposed intervention or control site status was determined before the invitations were extended. Intervention sites were invited first, to ensure their willingness to implement the ACP within the study. Subsequently, control sites were invited, matching for hospital size, urban or rural location and level of care. All 10 proposed sites agreed to participate. Intervention sites were Belleville General Hospital (Belleville, Ont.), Kingston General Hospital (Kingston, Ont.), Lake of the Woods District Hospital (Kenora, Ont.), Renfrew Victoria Hospital (Renfrew, Ont.) and Sudbury Regional Hospital (Sudbury, Ont.). Control sites were Lakeridge Hospital (Oshawa, Ont.), Owen Sound District Hospital (Owen Sound, Ont.), Public General Hospital of the Chatham-Kent Health Alliance (Chatham, Ont.), Prince Edward County Memorial Hospital (Picton, Ont.) and St. Joseph's Hospital (Hamilton, Ont.). Queen's University Health Sciences and Affiliated Teaching Hospital's Research Ethics Board (REB), as well as ethics boards and privacy officers from all participating sites, approved the study.

\section{Asthma care pathway}

Instructions for use of the ACP were printed on the package envelope. The ACP consisted of

- an outer envelope with instructions for use;

- a 2-page set of preprinted physician orders with medication guidelines on the back for reference;

- patient discharge instructions with

- quick facts on asthma on the back of the patient copy, and

- a teaching checklist for ED health care providers to complete on the back of the chart copy;

- a wall poster; and

- a pocket card.

The ACP was designed to complement participating hospitals' standard forms for triage and nursing documen- tation of vital signs, medication administration and progress notes. The revised adult ACP tools and materials are available from the Ontario Lung Association website (www.on.lung.ca/Health-Care-Professionals/EDACP /index.php).

\section{Asthma care pathway implementation at intervention sites}

The Ontario Lung Association designed and supported implementation of the ACP at intervention sites, based on the Registered Nursing Association of Ontario Toolkit: Implementation of Clinical Best Practice Guidelines..$^{20}$ Emergency department care providers (physicians, nurses and respiratory therapists [RTs]) and

Box 1. Expert Content Working Group representation

- Ontario Hospital Association

- Ministry of Health and Long-Term Care

- Canadian Association of Emergency Physicians

- Emergency Nurses Association of Ontario

- Ontario Lung Association

- Ontario Thoracic Society

- Ontario Respiratory Care Society

- Ontario College of Family Physicians

- Family Physicians' Airways Group of Canada

- Respiratory Therapy Society of Ontario

Box 2. Fundamental components of emergency department asthma care incorporated into the asthma clinical pathway

- Accurate assessment of asthma severity

- Appropriate triage assessment

- Basic history taken

- Frequent monitoring of vital signs and oxygen saturation

- Objective measures of lung function (spirometry or peak flow)

- Appropriate treatment in the ED

- Appropriate time for triage

- Timely use of short-acting $\beta$-agonists

- Systemic steroids in all but the mildest cases

- Appropriate management of severe, life-threatening and refractory cases

- Appropriate prescriptions on discharge

- Access to adequate supply of $\beta$-agonists

Prescription for inhaled and/or oral corticosteroids

- Appropriate education in the ED

- Teaching checklist completed

- Comprehensive discharge instructions

- Follow-up care arrangements made and discussed

$E D=$ emergency department 
administrative staff at each intervention site were invited to participate in interactive peer-facilitated casebased workshops. Approximately $50 \%$ of nurses and more than $75 \%$ of RTs attended the workshops; however, physician attendance was poor at the 2 largest sites. No incentives were given to use the ACP. Sites were encouraged to identify 1 or more site "champions" during the study to promote and support the use of the ACP to other staff.

Control sites administered usual care and did not receive copies of or training on the ACP. Site investigators and individual(s) responsible for determining each site's ability to participate were aware of their participation as a control site. In most instances, the responsible individual(s) were senior hospital physicians or nurse administrators (e.g., chief executive officer, chief of staff) or non-ED site investigators (e.g., respirologist). Emergency department clinical staff were unaware of the study.

Inclusion criteria were identical to that of the baseline OARV study. ${ }^{6}$ Patients eligible for use of the ACP were adults ( $\geq 19 \mathrm{yr}$ ) presenting for treatment of symptoms of an acute exacerbation of asthma. The recommended process was for triage staff to initiate the pathway and place the tools on the chart; any nurse, physician or RT involved in the patient's care could initiate the ACP even after triage.

\section{Data collection}

The study intervention (follow-up) period was from Jan. 9 to Jun. 8, 2006. Preintervention (baseline) data were obtained from the OARV study database ( 8 sites) or retrospective chart review (2 sites) for corresponding calendar dates (Jan. 9-Feb. 28, 2002, and Mar. 1-Jun. 8, 2001). Research assistant (RA) training, case identification and subject participation was performed in the same manner used in the OARV study. ${ }^{6,9}$

Research assistants regularly reviewed ED log books to identify adult patients who had a disposition diagnosis of asthma or "reactive airway disease" on the ED sheet, and received treatment for an acute exacerbation of asthma. Patients who had asthma coexistent with chronic obstructive pulmonary disease (COPD) were eligible for inclusion in the study. Eligible patients were mailed an introductory letter and consent form, and were contacted by telephone 1-3 weeks later and invited to provide informed consent and participate in the study. Participants then completed an abbreviated (10-15 $\mathrm{min})$ version of the questionnaire validated by the Ontario Respiratory Outcomes Research Network for the OARV study. ${ }^{9}$ The questionnaire captured information about asthma history including duration, triggers, access to care, previous health care use, severity, control, action plan use and pre-ED management. Minor alterations were made to the questionnaire to capture specifics of the pathway (e.g., a teaching checklist and recollection of teaching done in ED). Detailed chart abstractions similar to those conducted in the OARV study were performed for all visits.

Visit dates, disposition status, age, sex and postal code were collected for all eligible ED asthma visits. Repeat visits by individuals were included. Repeat visits within 14 days were considered the same episode and did not require a repeat interview or repeated consent. Questionnaire and chart abstraction data were entered by RAs into a Web-based data entry system (ED Asthma Care Electronic Data Capturing System, 3E Innovations).

\section{Statistical analysis}

Patient characteristics were compared at baseline and follow-up between participants and nonparticipants, and between participants at intervention versus control sites. Additionally, for the intervention sites participants were compared by pathway use. Age was compared between groups using the Wilcoxon-MannWhitney test, and the remaining dichotomous and polytomous variables were compared using the Fisher exact test and the $\chi^{2}$ test, respectively. Three measures of asthma severity were electronically derived from the data: 1) disease severity, based on the Canadian Asthma Consensus Guidelines definition including maintenance medication, ${ }^{18}$ 2) exacerbation severity based on the Canadian ED Triage and Acuity Scale (CTAS) classification and 3) exacerbation severity based on CTS and CAEP criteria. ${ }^{17}$

Outcomes were established a priori. The primary outcomes were ACP use and systemic steroid use in the ED. Secondary outcomes were 1) PEFR and oxygen saturation measurement; 2) time to nurse and physician assessment; 3) time to first bronchodilator; 4) use of anticholinergics in the ED; 5) administration of bronchodilators by metered-dose inhaler (MDI); 6) teaching delivered in ED; 7) systemic steroid prescription on discharge; 8) new prescription or increased dosage of inhaled steroid on discharge; 9) referral to specialized asthma service (i.e., a specialist or asthma educator) on discharge; 10) proportion of participants admitted; 11) length of 
stay in the ED; and 12) the proportion of repeat ED visits for asthma within 24 hours, 72 hours and 7 days. The sample size achieved in this study provided at least $80 \%$ power at $\alpha=0.01$ to detect a $20 \%$ difference in system steroid use between patients on the ACP versus patients not on the ACP.

An intent-to-treat (ITT) analysis was performed, comparing the change from baseline to follow-up between the intervention and control sites, including all visits regardless of ACP usage. The interaction between time period (baseline v. follow-up) and group (intervention site v. control site) provided odds ratios (for binary variables) generated to evaluate the difference in the change between groups. A second analysis compared the patients on the ACP with those not on the ACP using only the intervention sites at follow-up.
For binary variables, both analyses were performed by exact logistic regression conditioning on site. Since the time variables (including length of stay) were skewed, they were rank transformed and then analyzed by analysis of variance blocking by site. Because of its skewed distribution, length of stay is described by its geometric mean. These analyses treat the site as a fixed effect, and, thus, inference is limited to the 10 sites and 2 time periods observed. To confirm the findings, the entire analysis was repeated treating site as a random effect by using a generalized linear mixed effects model with a logit link for binary variables and a linear mixed effect model on rank transformed data for the time variables. The mixed model accounts for clustering due to within-site correlation, and, thus, allows inference beyond the 10 observed sites to a broader population

\section{Control sites $(n=5)$}

\section{Intervention sites $(n=5)$}

\section{Baseline}

Visits and hospital admissions

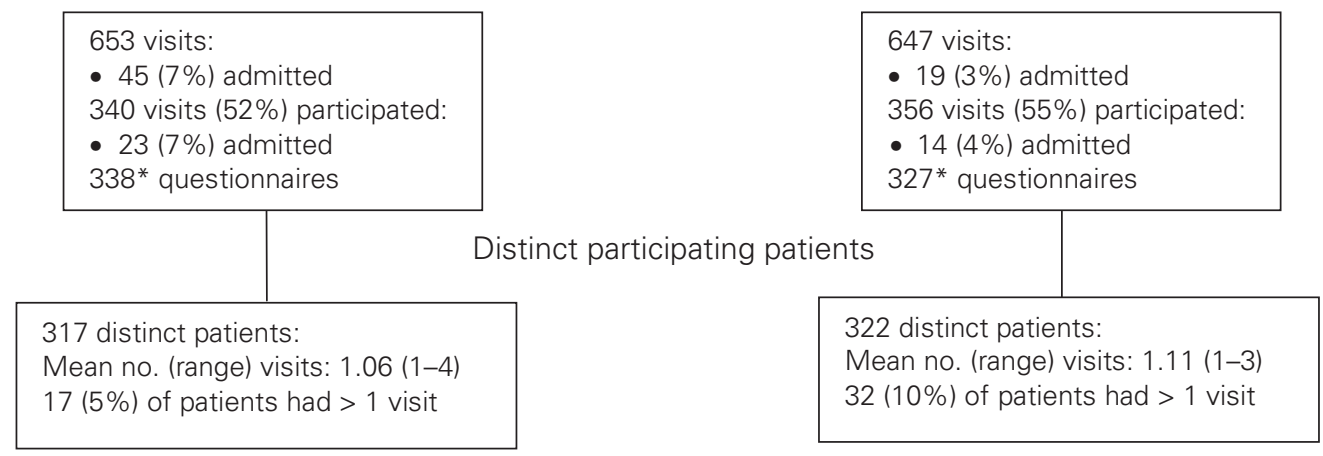

\section{Follow-up}

Visits and hospital admissions

540 visits:

- $28(5 \%)$ admitted

349 visits (65\%) participated:

- $22(6 \%)$ admitted

$325^{*}$ questionnaires
553 visits:

- 44 (8\%) admitted:

384 visits (69\%) participated:

- $36(9 \%)$ admitted

363* questionnaires

Distinct participating patients

297 distinct patients:

Mean no. (range) visits: $1.18(1-7)$

$36(12 \%)$ had > 1 visit
326 distinct patients:

Mean no. (range) visits: $1.18(1-7)$

$37(11 \%)$ had > 1 visit

Fig. 1. Identification of emergency department visits, hospital admissions, participation status and distinct patients at intervention and control sites at baseline and follow-up. *Only 1 questionnaire was required for repeat visits within 2 weeks. 
of similar sites. To assess the impact of multiple visits, the analysis was done including and excluding repeat visits. All tests were 2 -sided, and a $p$ value $<0.01$ was considered statistically significant, which for this data corresponds to a false discovery rate of approximately $5 \% . .^{21}$ All analyses were performed using SAS V9.1 (SAS Institute Inc.).

\section{RESULTS}

Asthma ED visits and participant visits from control and intervention sites at baseline and follow-up are illustrated in Figure 1. Overall participation rate based on all ED visits was $60 \%$. Compared with nonparticipants, participants had comparable discharge diagnoses, were more commonly female and at follow-up were slightly older and more commonly admitted (Table 1). The number of participant visits and patients at each site and time period are outlined in Table 2. The sample size by use of the ACP at intervention sites at follow-up is outlined in Figure 2. Exclusion of repeat visits did not significantly alter the results, hence the results for all visits are reported. Participants at control and intervention sites at baseline and follow-up were similar, except that intervention site participants at baseline had seen an asthma specialist less often and had more severe asthma exacerbations by CTAS score (Table 3).

\section{Asthma care pathway use}

Asthma care pathway use varied significantly by site, ranging from $6 \%$ to $60 \%(p<0.001$; Table 2$)$. There were no significant differences in ACP use by participant age or sex, day of the week or disease severity. The ACP was used less often between midnight and 6 am than at other times of day $(11 \%$ v. $29 \%, p=0.005)$ and for neardeath or life-threatening exacerbations according to the CAEP and CTS criteria (10\% v. 30\%, $p=0.047)$ and CTAS criteria $(10 \%$ v. $27 \%, p=0.08)$. There was a negative correlation between pathway use and the total number of patient (or participant) visits ( $n=5$, Spearman rank correlation coefficient $=-0.9, p=0.038$ ).

\section{Emergency department management}

The results for ED management are presented in Table 4 and Figure 3. In the ITT analysis, significant increases were found in intervention sites compared with control sites in arterial blood gas measurement $(p<$ $0.001)$, the use of bronchodilators by MDI $(p<0.001)$, the use of inhaled steroids $(p<0.001)$ and the use of oxygen $(p=0.001)$. Increases in the use of systemic steroids (i.e., oral and intravenous or either) were consistently greater in intervention compared with control groups, but the magnitude of these differences was not statistically significant.

In intervention sites at follow-up, patients on the ACP more commonly had PEFR measured and had an RT participate in their care, when compared with patients not on the ACP. The use of systemic steroids in the ED increased significantly at intervention sites when the ACP was used $(p<0.001$; Table 4, Fig. 3C).

Documentation of PEFR declined in both intervention and control sites from baseline to follow-up $(p=$ 0.001 and $p=0.011$, respectively). These decreases in PEFR documentation were not significantly different

\begin{tabular}{|c|c|c|c|c|c|c|c|}
\hline \multirow[b]{2}{*}{ Characteristic } & \multicolumn{4}{|c|}{ Baseline, no. (\%) of participants* } & \multicolumn{3}{|c|}{ Follow-up, no. (\%) of participants* } \\
\hline & $\begin{array}{c}\text { Nonpar } \\
\quad n=\end{array}$ & $\begin{array}{l}\text { ticipants, } \\
=604\end{array}$ & $\begin{array}{c}\text { Participants, } \\
n=696\end{array}$ & $p$ value & $\begin{array}{c}\text { Nonparticipants, } \\
n=360\end{array}$ & $\begin{array}{c}\text { Participants } \\
n=733\end{array}$ & $p$ value \\
\hline Mean age, yr (SD) & 40.9 & $(17.1)$ & $41.4(16.1)$ & 0.30 & $39.1(16.3)$ & 43.2 (17.3) & $<0.001$ \\
\hline Female & 360 & $(59.6)$ & $472(67.8)$ & 0.002 & $208(57.8)$ & 504 (68.8) & $<0.001$ \\
\hline Admitted & 27 & (4.5) & 37 (5.3) & 0.52 & 14 (3.9) & $58 \quad(7.9)$ & 0.013 \\
\hline Discharge diagnosis & & & & 0.17 & & & 0.32 \\
\hline Missing & 0 & $(0.0)$ & $2(0.3)$ & & $3 \quad(0.8)$ & $1 \quad(0.1)$ & \\
\hline Asthma & 436 & $(72.2)$ & $509(73.1)$ & & $272(75.6)$ & 559 (76.3) & \\
\hline COPD/asthma & 19 & (3.1) & $12(1.7)$ & & $17 \quad(4.7)$ & $26 \quad(3.5)$ & \\
\hline RAD & 141 & (23.3) & $156(22.4)$ & & $60(16.7)$ & $134(18.3)$ & \\
\hline Possible asthma & 8 & (1.3) & $17 \quad(2.4)$ & & $8 \quad(2.2)$ & 13 & \\
\hline
\end{tabular}


between intervention and control sites $(p=0.45)$. At follow-up, PEFR was documented more commonly in participants on the ACP versus those not on the ACP within the first hour of presentation, and before discharge ( $p<0.001$; Table 4, Fig. 3A).

Information about RT consultation was not collected in the baseline study. At follow-up, RTs were only on staff in EDs at 6 sites (3 control and 3 intervention). Respiratory therapists were consulted more commonly

Table 2. Number of participant visits and patients at baseline and follow-up

\begin{tabular}{|c|c|c|c|c|c|}
\hline \multirow{3}{*}{$\begin{array}{l}\text { Site } \\
\text { matched } \\
\text { pairs }\end{array}$} & \multicolumn{2}{|c|}{ Baseline } & \multicolumn{3}{|c|}{ Follow-up } \\
\hline & & & & & ervention \\
\hline & Control & Intervention & Control & Overall & ACP no. (\%) \\
\hline 1 & 177 & 184 & 66 & 117 & $30 \quad(26)$ \\
\hline 2 & 92 & 55 & 102 & 120 & $7 \quad(6)$ \\
\hline 3 & 16 & 37 & 70 & 52 & $31 \quad(60)$ \\
\hline 4 & 23 & 58 & 51 & 65 & $21 \quad(32)$ \\
\hline 5 & 32 & 22 & 60 & 30 & 12 (40) \\
\hline $\begin{array}{l}\text { Total } \\
\text { visits }\end{array}$ & 340 & 356 & 349 & 384 & $101 \quad(26)$ \\
\hline $\begin{array}{l}\text { Distinct } \\
\text { patients }\end{array}$ & 317 & 322 & 297 & 326 & 83 (25) \\
\hline
\end{tabular}

for patients on the ACP ( $p<0.001$; Table 4, Fig. 3E). Inhaler teaching increased significantly from baseline to follow-up in the intervention arm only and was more commonly documented for patients on the ACP compared with those not on the ACP.

The times to first dose of a bronchodilator and of systemic steroid were similar between intervention and control sites at baseline and did not change significantly at follow-up. The overall median time to the first dose of the bronchodilator or systemic steroid were 0.9 (site range 0.4-1.6) hours and 1.4 (site range 0.7-2.2) hours, respectively.

Adherence to CTAS guidelines for the time to see a nurse, time to see a physician and documentation of oxygen saturation for the initial assessment of asthma in intervention and control sites ranged from $0 \%$ to $13 \%$ for CTAS I, II and III. There were no consistent differences apparent in overall compliance from baseline to follow-up in intervention or control sites. Concordance with specific components of CTAS guidelines was highest for documentation of oxygen saturation (range $95 \%-100 \%)$ and time to see a nurse within the time frames recommended for the CTAS severity (range $75 \%-100 \%$ ). Time to see a physician usually did not meet CTAS recommendations for any CTAS severity at baseline or follow-up (range 6\%-47\%).

Table 3. Participant characteristics at baseline and follow-up

\begin{tabular}{|c|c|c|c|c|c|c|}
\hline \multirow[b]{2}{*}{ Characteristic } & \multicolumn{3}{|c|}{ Baseline, \% of participants* } & \multicolumn{3}{|c|}{ Follow-up, \% of participants* } \\
\hline & Control & Intervention & $p$ value & Control & Intervention & $p$ value \\
\hline Mean age, yr (SD) & $41.0(16.2)$ & $41.7(16.1)$ & 0.48 & $43.3(17.0)$ & $43.1(17.5)$ & 0.77 \\
\hline Female & 70.0 & 65.7 & 0.26 & 66.2 & 71.1 & 0.18 \\
\hline Admitted & 6.8 & 3.9 & 0.13 & 6.3 & 9.4 & 0.13 \\
\hline Doctor diagnosed asthma & 79.6 & 76.8 & 0.41 & 79.4 & 84.3 & 0.09 \\
\hline Median asthma duration, yr & 14.0 & 14.0 & 0.63 & 12.0 & 11.5 & 0.63 \\
\hline Has doctor for asthma care & 78.4 & 91.7 & $<0.001$ & 80.9 & 79.9 & 0.77 \\
\hline GINA asthma disease severity & & & 0.17 & & & 0.14 \\
\hline Mild & 36.1 & 33.3 & & 28.6 & 32.5 & \\
\hline Moderate & 26.9 & 33.6 & & 32.9 & 26.2 & \\
\hline Severe & 37.0 & 33.0 & & 38.5 & 41.3 & \\
\hline Ever seen asthma specialist & 40.8 & 30.9 & 0.008 & 39.7 & 41.3 & 0.70 \\
\hline Previous asthma education & 14.2 & 11.3 & 0.30 & 15.1 & 20.4 & 0.07 \\
\hline Asthma education before ED visit & 82.5 & 84.7 & 0.60 & 86.2 & 84.8 & \\
\hline Current smoker & 32.8 & 23.9 & 0.028 & 30.2 & 23.7 & 0.67 \\
\hline CTAS exacerbation severity & & & $<0.001$ & & & 0.09 \\
\hline CTAS 1 (Life-threatening) & 3.5 & 2.7 & & 5.4 & 5.5 & 0.79 \\
\hline CTAS 2 (Severe) & 30.3 & 48.5 & & 37.5 & 39.9 & \\
\hline CTAS 3 (Mild/moderate) & 66.2 & 48.8 & & 57.0 & 54.6 & \\
\hline
\end{tabular}




\section{Discharge management}

Table 5 summarizes the management of patients discharged from the ED. In the ITT analysis, follow-up with a pre-existing asthma specialist or new referral to an asthma service (specialist or education centre or program) increased significantly in the intervention sites ( $p<0.001$; Table 5, Fig. 4C). On discharge, prescriptions for a new systemic corticosteroid or to increase the current dose of systemic steroid were significantly higher among those on the ACP versus those who were not $(p<0.001$; Table 5, Fig. 4A). Documentation of inhaler or device teaching increased significantly in both analyses (both $p<0.001$ ).

\section{Administrative and clinical outcomes}

Administrative and clinical outcomes are summarized in Table 6 and Figure 4. From baseline to follow-up, the admission rates remained nearly stable in the control sites, but increased from $3.9 \%$ to $9.4 \%$ in the intervention sites $(p=0.016)$. Admission percentages were comparable in patients who were on the ACP versus those who were not $(p=0.91)$.

The difference in the change in ED length of stay was slightly more between intervention and control sites overall (difference in geometric mean $=30 \mathrm{~min}, p=$ 0.056) and for patients who were on the ACP versus those who were not (difference in geometric mean = $16 \mathrm{~min}, p=0.002$; Fig. 4F).

Repeat ED visit rates tended to increase from baseline to follow-up in both groups, but these differences were not statistically significant either in or between intervention or control sites in the ITT analysis, or between patients who were on the ACP versus those who were not.

Finally, recollection of teaching provided in the ED was greater for almost all components of education at intervention compared with control sites, particularly in those on the ACP versus those who were not. Self-reported adherence with physician follow-up was not significantly different between the control and intervention sites or between patients who were on the ACP versus those who were not (Table 6).

\section{Generalized linear mixed effects model}

The mixed effects model confirmed significantly greater changes in certain management practices and patient outcomes at intervention compared with control sites from baseline to follow-up (Table 7).

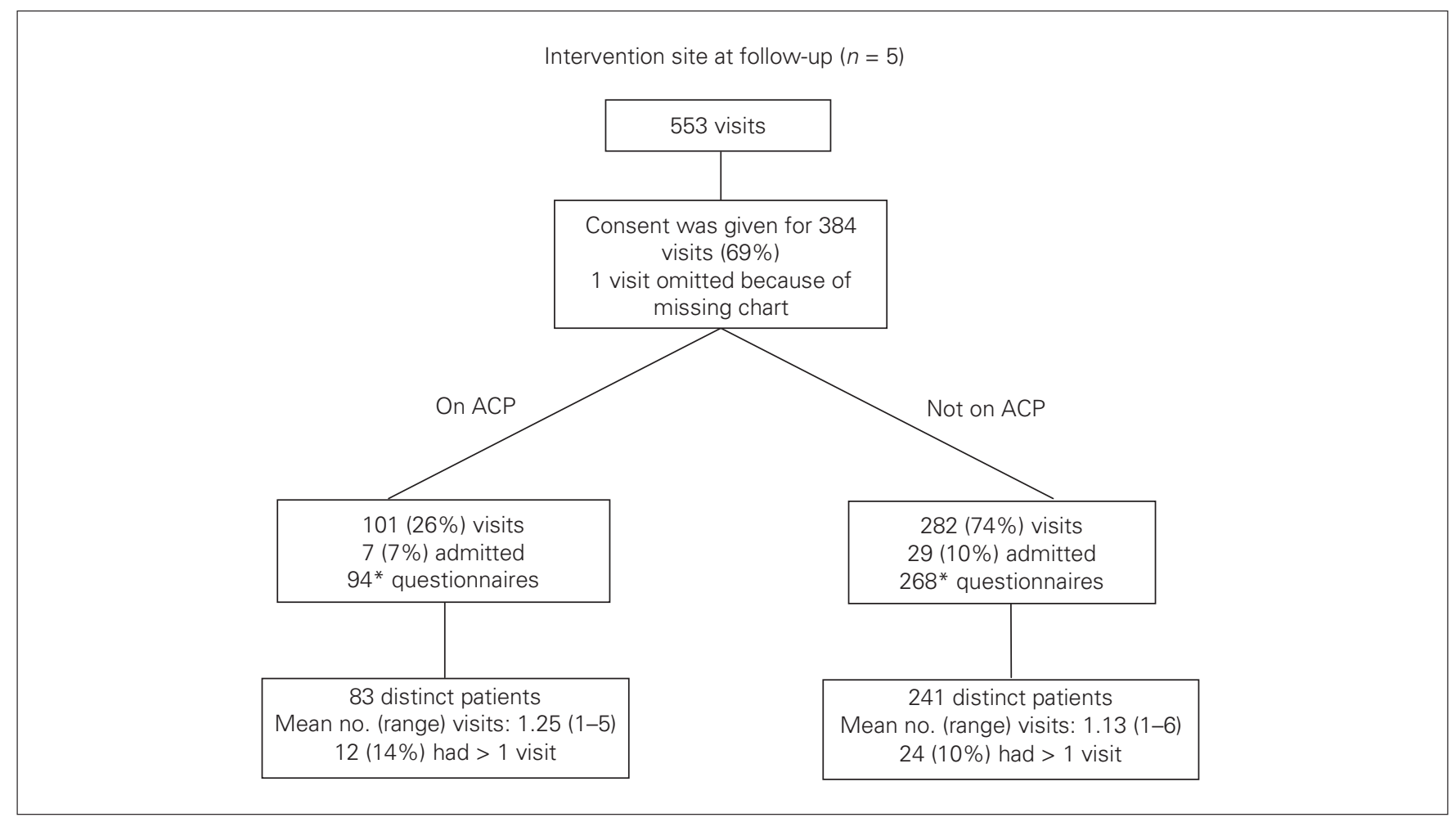

Fig. 2. Sample size by use of asthma care pathway (ACP) at intervention sites at follow-up. *Only 1 questionnaire was required for repeat visits within 2 weeks. 
The mixed model also confirmed significantly higher odds of certain management practices and outcomes in individuals who were on the ACP versus those who were not on the ACP at intervention sites at follow-up (Table 8).

\section{DISCUSSION}

To our knowledge this is the first Canadian multicentre study evaluating the implementation of a standardized evidence-based ED ACP for adults. Uptake of the ACP in the 5 study sites was highly variable, ranging from $6 \%$ to $60 \%$, with an average of $26 \%$ over 5 months. An ITT analysis revealed significant improvements in certain ED management practices, including arterial blood gas measurement, the use of bronchodilators by MDI rather than nebulizer, inhaled steroids and oxygen administration in ED and referrals to an asthma specialist or service on discharge. Documentation and recollection of inhaler device education in the ED improved in both the ITT analysis and in patients who were on the ACP versus those who were not. Admission percentage increased in intervention sites compared with controls, but not in those patients who were on the ACP versus those who were not. Outcomes such as PEFR documentation, RT consultation and the use of systemic steroids in the ED and on discharge improved in patients who were managed on the ACP, but did not improve overall at the intervention sites. Length of stay was approximately 16 minutes longer in patients who were on the ACP versus those who were not. Further study is warranted to determine whether outcomes can be further improved if barriers to uptake can be overcome.

The multicentre design and the elaborate pre-post comparison including a control group were major strengths of our study. The inclusion of a control group addresses the possibility of changes in practice patterns

\begin{tabular}{|c|c|c|c|c|c|c|c|c|c|c|}
\hline \multirow[b]{3}{*}{ Management } & \multicolumn{4}{|c|}{$\%$ of patients } & \multirow{2}{*}{\multicolumn{2}{|c|}{ Difference in change }} & \multirow{2}{*}{\multicolumn{4}{|c|}{$\frac{\% \text { of patients }}{\text { Intervention at follow-up }}$}} \\
\hline & \multicolumn{2}{|c|}{ Baseline } & \multicolumn{2}{|c|}{ Follow-up } & & & & & & \\
\hline & $\begin{array}{l}\text { Control, } \\
n=340\end{array}$ & $\begin{array}{c}\text { Intervention, } \\
n=356\end{array}$ & $\begin{array}{l}\text { Control, } \\
n=349\end{array}$ & $\begin{array}{c}\text { Intervention } \\
n=384\end{array}$ & OR* $(95 \% \mathrm{Cl})$ & $p$ value* & \multicolumn{2}{|c|}{$\begin{array}{l}\text { No ACP, } \quad \text { ACP, } \\
n=282 \quad n=101\end{array}$} & OR (95 \% Cl) & $p$ value \\
\hline $\begin{array}{l}\text { PEFR } \\
\text { measured }\end{array}$ & 47.5 & 56.5 & 37.0 & 44.6 & $1.20(0.76-1.90)$ & 0.452 & 31.9 & 80.2 & 7.05 (3.95-12.56) & $<0.001 \dagger$ \\
\hline $\begin{array}{l}\text { Oxygen } \\
\text { saturation } \\
\text { recorded }\end{array}$ & 97.7 & 97.2 & 98.3 & 98.7 & $2.10(0.42-10.51)$ & 0.322 & 99.7 & 96.0 & $0.08(0.01-0.98)$ & $0.021 \ddagger$ \\
\hline $\begin{array}{l}A B G \\
\text { measured }\end{array}$ & 5.3 & 1.1 & 2.9 & 3.9 & $10.23(2.51-41.76)$ & $0.001 \dagger$ & 4.3 & 3.0 & $0.68(0.18-2.57)$ & 0.648 \\
\hline $\begin{array}{l}\text { Chest } \\
\text { radiography }\end{array}$ & 47.5 & 37.6 & 43.8 & 44.1 & $1.28(0.82-2.01)$ & 0.277 & 46.1 & 38.6 & $0.70(0.42-1.17)$ & $0.182 \ddagger$ \\
\hline $\begin{array}{l}\text { Salbutamol } \\
\text { by MDI }\end{array}$ & 52.4 & 2.2 & 36.7 & 30.5 & $23.99(10.05-57.31)$ & $<0.001 \neq$ & 25.2 & 45.5 & $1.76(1.01-3.04)$ & $0.047 \ddagger$ \\
\hline $\begin{array}{l}\text { Ipratropium } \\
\text { bromide by } \\
\text { MDI }\end{array}$ & 47.9 & 0.8 & 27.8 & 19.1 & $50.24(14.52-173.86)$ & ) $<0.001 \dagger$ & 15.2 & 29.7 & $1.68(0.94-3.01)$ & $0.084 \ddagger$ \\
\hline $\begin{array}{l}\text { Systemic } \\
\text { steroid (PO } \\
\text { or IV) }\end{array}$ & 33.5 & 34.3 & 41.8 & 51.2 & $1.48(0.93-2.36)$ & 0.109 & 45.4 & 67.3 & 3.20 (1.82-5.62) & $<0.001 \dagger$ \\
\hline $\begin{array}{l}\text { Inhaled } \\
\text { steroids (Neb } \\
\text { or MDI) }\end{array}$ & 11.5 & 6.2 & 22.1 & 34.5 & 7.65 (3.55-16.48) & $<0.001$ & 39.0 & 21.8 & $1.33(0.59-2.96)$ & 0.479 \\
\hline Antibiotics & 4.1 & 5.6 & 6.6 & 5.0 & $0.49(0.18-1.34)$ & 0.169 & 6.0 & 2.0 & $0.43(0.09-2.00)$ & 0.288 \\
\hline Oxygen & 13.8 & 5.6 & 12.0 & 11.0 & $3.43(1.62-7.25)$ & 0.001 & 11.7 & 8.9 & $0.91 \quad(0.40-2.06)$ & 0.919 \\
\hline RT consulted & & & 23.8 & 17.8 & $0.69(0.48-0.99)$ & 0.040 & 11.3 & 35.6 & $18.89(5.51-64.77)$ & $<0.001 \dagger$ \\
\hline \multicolumn{11}{|c|}{$\begin{array}{l}\mathrm{ACP}=\text { asthma care pathway; } \mathrm{ABG}=\text { arterial blood gases; } \mathrm{Cl}=\text { confidence interval; } \mathrm{ED}=\text { emergency department; } \mathrm{IV}=\text { intravenous; } \mathrm{MDI}=\text { metered dose inhaler; } \mathrm{Neb}=\mathrm{Nebulizer} ; \\
\mathrm{OR}=\text { odds ratio; } \mathrm{PEFR}=\text { peak expiratory flow rate; } \mathrm{PO}=\text { per os; } \mathrm{RT}=\text { respiratory therapist. } \\
\text { *The } \mathrm{OR} \text { and } p \text { values are for the interaction between the period and group effect as estimated by exact logistic regression conditioning on site. The } \mathrm{OR} \text { estimates the number of times } \\
\text { more the odds increased from baseline to follow-up in the intervention group compared to the control group after conditioning on site. } \\
+p \text { value }<0.01 \text { from logistic mixed effects model with random site. } \\
\neq p \text { value between } 0.1 \text { and } 0.01 \text { logistic mixed effects model with random site. }\end{array}$} \\
\hline
\end{tabular}


that may have occurred during the study period in the absence of the intervention. Thus our study represents a major advance over previous noncontrolled or single- centre evaluations of the impact of care maps or pathways. ${ }^{13,14,22,23}$ In addition, the mixed model analysis adds confidence to the generalizability of the key results in
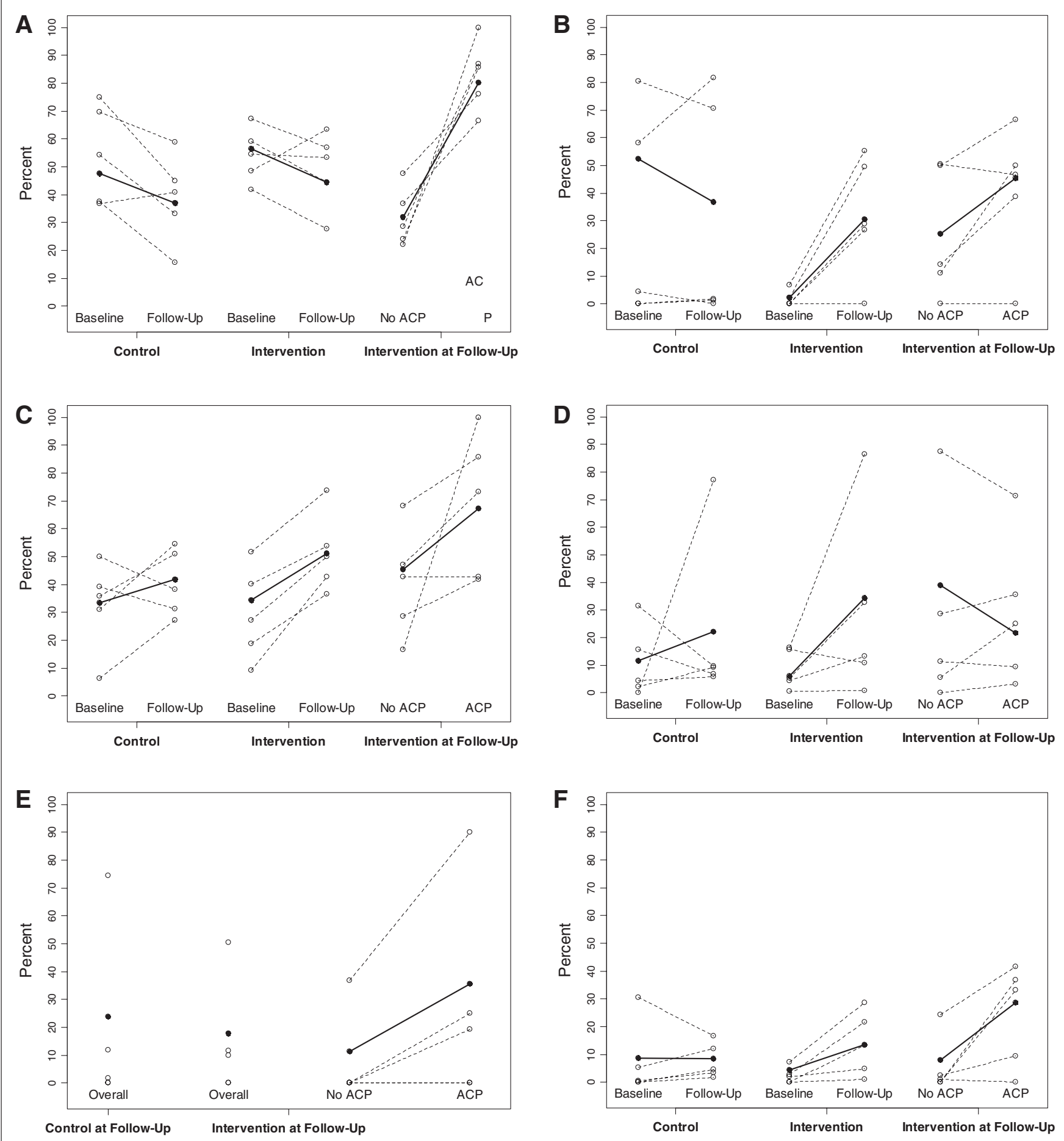

Fig. 3. Emergency department (ED) management at baseline and follow-up in control and intervention sites, and individual sites by asthma care pathway (ACP) use at intervention sites at follow-up. Individual sites are represented by empty circles connected by dashed lines. Averages are depicted by solid circles and lines. Peak flow documented (first hour or last (A); salbutamol by metered-dose inhaler (MDI) in ED (B); systemic steroid (oral or intravenous) in ED (C); inhaled steroid (nebulizer or $\mathrm{MDI}$ ) in ED (D); respiratory therapist consulted in ED (E); inhaler teaching documented in ED (F). 
the intervention sites compared with the control sites (bronchodilator administration by MDI, referrals and recollection of ED education) and in individuals who were on the pathway versus those who were not (PEFR documentation, bronchodilator administration by MDI, systemic steroid administration in ED and on discharge, RT consultation, documentation of inhaler teaching and recollection of education provided in the ED).

\section{Limitations}

Several limitations of the study must be considered. First, our nonrandomized sampling and allocation undermines the ability to make causal inferences from our findings. Second, our power was limited to detect small to moderate effect sizes. As a result, it is conceivable that our failure to detect some statistically significant differences represent type II errors. Finally, the ACP use versus nonuse comparison is subject to selection bias, since health care providers who used the ACP may already have been more adherent to asthma guidelines. Separating the effects of the provider who used the ACP from the ACP (tool) itself is not possible with our design.

Some may consider the $26 \%$ average adoption of the ACP a failure. In light of the challenges of implementing standardized tools and training of multiple sites, professions and providers in a short time period, we feel this adoption rate is not surprising. It is noteworthy that renovations at the site with lowest ACP use undoubtedly interfered with uptake. The uptake of $60 \%$ at the smallest site is encouraging. Barriers to uptake for the ACP were evaluated in detail in a separate study. ${ }^{24}$ Our finding of an inverse relationship between pathway use and site size is not surprising. Applying knowledge translation principles, ${ }^{10,11,20}$ future uptake of the ACP may be improved by obtaining formal endorsement from the professional organizations involved in its development, collaborating with local and regional health system administrators to design an implementation strategy, assessing each site's readiness to adopt a pathway, addressing site-specific barriers (e.g., human resources, equipment) and the adaptation of aspects of the ACP tools to meet site-specific needs. ${ }^{24}$

The improvements in adherence to certain aspects of ED management guidelines and patient outcomes at intervention sites is consistent with single-centre studies. ${ }^{13,14,22,23}$ It is unclear why PEFR documentation declined at follow-up in both the intervention and control sites. However, it is noteworthy that there was no significant difference in this decline between intervention and control sites. This illustrates the importance of having a control group, without which one might erroneously attribute differences in practice to the intervention. Several sites began using spirometry in lieu of peak flow metres during the study period. It is conceivable that staff did not perform peak flows (e.g., if they were awaiting spirometry), did not chart on spirometric peak

Table 5. Comparison of discharge management between intervention and control sites and by asthma care pathway use versus nonuse at intervention sites

\begin{tabular}{|c|c|c|c|c|c|c|c|c|c|c|}
\hline \multirow[b]{3}{*}{ Management } & \multicolumn{4}{|c|}{$\%$ of patients } & & & \multirow{2}{*}{\multicolumn{4}{|c|}{$\frac{\% \text { of patients }}{\text { Intervention at follow-up }}$}} \\
\hline & \multicolumn{2}{|c|}{ Baseline } & \multicolumn{2}{|c|}{ Follow-up } & \multicolumn{2}{|c|}{ Difference in change } & & & & \\
\hline & $\begin{array}{l}\text { Control, } \\
n=317\end{array}$ & $\begin{array}{l}\text { Intervention, } \\
n=342\end{array}$ & $\begin{array}{l}\text { Control, I } \\
n=327\end{array}$ & $\begin{array}{c}\text { Intervention, } \\
n=347\end{array}$ & $\mathrm{OR}^{*}(95 \% \mathrm{Cl})$ & $p$ value* & $\begin{array}{l}\text { No ACP, } \\
n=253\end{array}$ & $\begin{array}{l}\text { ACP, } \\
n=94\end{array}$ & $\mathrm{OR}^{*}(95 \% \mathrm{Cl}) p$ & $b$ value* \\
\hline $\begin{array}{l}\text { New medication at } \\
\text { discharge }\end{array}$ & 74.1 & 66.7 & 68.2 & 72.0 & $1.46(0.87-2.43)$ & 0.136 & 68.0 & 83.0 & $1.69(0.89-3.20)$ & $0.108 \dagger$ \\
\hline $\begin{array}{l}\text { Systemic steroid } \\
\text { added/increased }\end{array}$ & 33.4 & 40.8 & 40.7 & 44.7 & $1.08(0.67-1.75)$ & 0.761 & 37.5 & 63.8 & $2.47(1.44-4.23)<$ & $<0.001 \neq$ \\
\hline $\begin{array}{l}\text { Inhaled steroid added/ } \\
\text { increased }\end{array}$ & 22.2 & 19.2 & 32.1 & 34.9 & $1.35(0.79-2.30)$ & 0.250 & 33.2 & 39.4 & $1.40(0.82-2.40)$ & 0.239 \\
\hline $\begin{array}{l}\text { Follow-up with or new } \\
\text { referral to asthma } \\
\text { specialist or service }\end{array}$ & 11.7 & 3.8 & 17.4 & 26.5 & $15.27(6.69-34.88)$ & $<0.001 \ddagger$ & 26.1 & 27.7 & $1.14(0.61-2.15)$ & 0.688 \\
\hline $\begin{array}{l}\text { Inhaler/device teaching } \\
\text { documented }\end{array}$ & 8.8 & 4.4 & 8.6 & 13.5 & $7.45(3.12-17.78)$ & $<0.001$ & 7.9 & 28.7 & $4.32(2.06-9.07)<$ & $<0.001 \neq$ \\
\hline \multicolumn{11}{|c|}{ 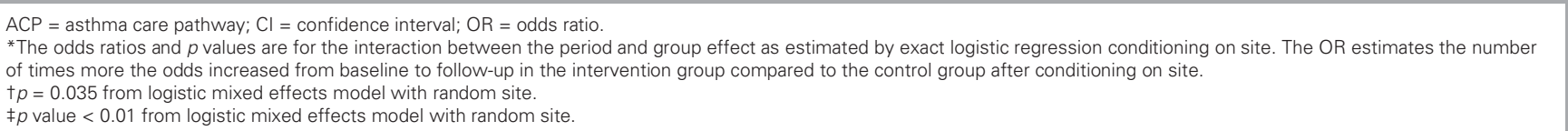 } \\
\hline
\end{tabular}


flows, or RAs were unable to locate spirometry printouts for abstraction. Notably, PEFR documentation at all 5 intervention sites was consistently higher in pa- tients who were on the ACP versus those who were not.

There were no consistent differences in the changes from baseline to follow-up between patients who were
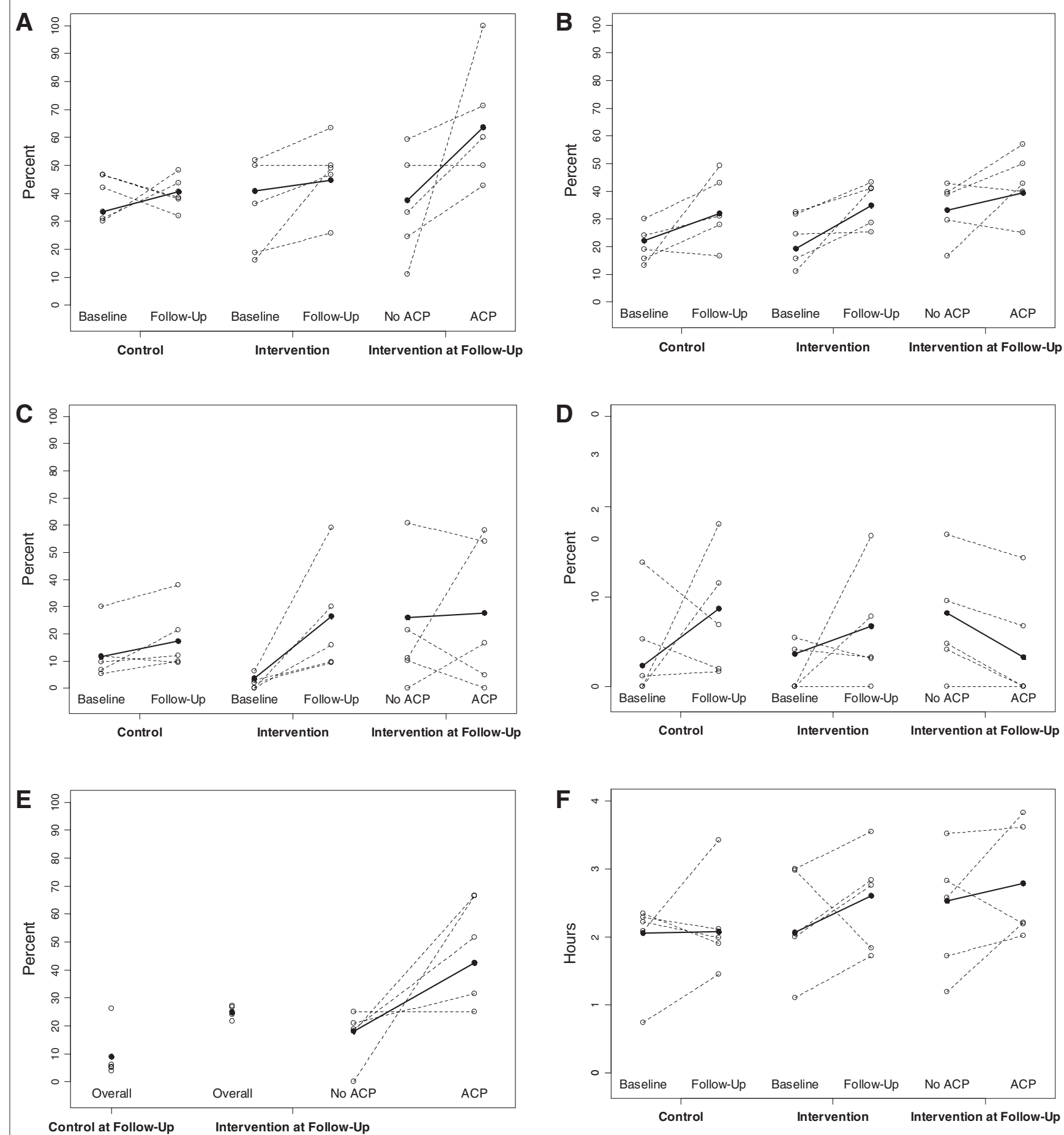

Fig. 4. Discharge management and patient outcomes at baseline and follow-up in control and intervention sites and by asthma care pathway (ACP) use at intervention sites at follow-up. Individual sites are represented by empty circles connected by dashed lines. Averages are depicted by solid circles and lines. Add or increase systemic steroid at discharge (A); add or increase inhaled steroid at discharge (B); follow-up or referral to specialist or asthma service (C); repeat emergency department (ED) visit within 7 days of discharge (D); recall of asthma teaching done in ED (E); length of stay (geomatric mean) (F). 
on the ACP versus those who were not in time to see a nurse, time to see a physician, or time to receive the first bronchodilator dose or systemic steroids. Although nursing assessment occurred within the CTAS level recommended time frames, efforts appear warranted to improve time to physician assessment.

The greater increase in admission percentage at intervention sites is unexplained and it is unclear whether this represents better or worse care. At baseline, intervention sites had more severe asthma exacerbations based on CTAS and CAEP and CTS criteria, yet they had lower admission percentages than the control sites. To the extent that repeat ED visits may be an indication that a patient may have merited earlier admission, it is possible that an increase in admission percentage in this sample represents improved care. Our finding of nonsignificant reductions in relapse rates in the intervention sites supports such an inference. However, the goal of ACPs should be to prevent admissions with prompt optimal care. Consequently, we believe the impact of ACPs on admission rates is a priority for future research.

Efficiency and quality of care are paramount in EDs. Although ED length of stay was longer in patients on the ACP, we believe that a 16-minute prolongation is acceptable in order to improve care and outcomes. The improvements in self-reported recall of almost all aspects of education received in the ED is encouraging, and would be expected to lead to improvements in asthma control and quality of life. Our findings add to

Table 6. Comparison of administrative and clinical outcomes between intervention and control sites and by asthma care pathway use versus nonuse at intervention sites

\begin{tabular}{|c|c|c|c|c|c|c|c|c|c|c|}
\hline \multirow[b]{3}{*}{ Outcome } & \multicolumn{4}{|c|}{$\%$ of patients } & \multirow{2}{*}{\multicolumn{2}{|c|}{ Difference in change }} & \multirow{2}{*}{\multicolumn{4}{|c|}{$\frac{\% \text { of patients }}{\text { Intervention at follow-up }}$}} \\
\hline & \multicolumn{2}{|c|}{ Baseline } & \multicolumn{2}{|c|}{ Follow-up } & & & & & & \\
\hline & $\begin{array}{l}\text { Control, } \\
n=340\end{array}$ & $\begin{array}{c}\text { Intervention } \\
n=356\end{array}$ & $\begin{array}{r}\text {, Control, } \\
n=349\end{array}$ & $\begin{array}{c}\text { Intervention, } \\
n=384\end{array}$ & $\mathrm{OR}^{*}(95 \% \mathrm{Cl})$ & $p$ value* & $\begin{array}{l}\text { No ACP, } \\
n=282\end{array}$ & $\begin{array}{c}\text { ACP } \\
n=101\end{array}$ & $\mathrm{OR}^{*}(95 \% \mathrm{Cl})$ & $p$ value* \\
\hline Admissions & 6.8 & 3.9 & 6.3 & 9.4 & $3.09(1.22-7.82)$ & 0.016 & 10.3 & 6.9 & $1.01(0.40-2.57)$ & 0.91 \\
\hline \multicolumn{11}{|l|}{ Repeat visits $\dagger$} \\
\hline $24 \mathrm{~h}$ & 1.6 & 0.7 & 3.4 & 1.6 & $1.75(0.23-13.4)$ & 0.48 & 1.8 & 1.1 & $1.24(0.13-12.22)$ & 0.79 \\
\hline $72 \mathrm{~h}$ & 2.3 & 2.9 & 5.6 & 3.5 & $0.88(0.24-3.33)$ & 0.87 & 4.5 & 1.1 & $0.33(0.04-2.87)$ & 0.32 \\
\hline $7 d$ & 2.3 & 3.6 & 8.7 & 6.7 & $0.68(0.21-2.22)$ & 0.47 & 8.2 & 3.3 & $0.46(0.12-1.80)$ & 0.30 \\
\hline $\begin{array}{l}\text { Self-reported recall of } \\
\text { teaching in the ED }\end{array}$ & & & 9.0 & 24.7 & $3.65(2.35-5.66)$ & $<0.001 \neq$ & 18.1 & 42.6 & $3.83(2.16-6.77)$ & $<0.001$ \\
\hline $\begin{array}{l}\text { Self-reported } \\
\text { adherence with } \\
\text { physician follow-up }\end{array}$ & & & 48.0 & 43.9 & $0.80(0.60-1.07)$ & 0.13 & 45.7 & 38.3 & $0.95(0.57-1.60)$ & 0.84 \\
\hline $\begin{array}{l}\text { ACP }=\text { asthma care pathway; } \\
{ }^{*} \text { The OR and } p \text { values are for } \\
\text { more the odds increased from } \\
\text { tFor discharged patients. } \\
\neq p \text { value }<0.01 \text { from logistic } n\end{array}$ & $\begin{array}{l}=\text { conf } \\
\text { intera } \\
\text { aseline }\end{array}$ & $\begin{array}{l}\text { dence interval; ED } \\
\text { tion between the } \\
\text { to follow-up in the } \\
\text { cts model with ra }\end{array}$ & $\begin{array}{l}\text { = emergenc } \\
\text { e period and } g \\
\text { e intervention } \\
\text { endom site. }\end{array}$ & $\begin{array}{l}\text { lepartment; } \\
\text { p effect as } \\
\text { oup compare }\end{array}$ & $\begin{array}{l}\text { dds ratio. } \\
\text { ed by exact logistic } r \\
\text { e control group after }\end{array}$ & gression & $\begin{array}{l}\text { onditionin } \\
\text { g on site. }\end{array}$ & ite. Th & estimates the num & r of times \\
\hline
\end{tabular}

Table 7. Generalized linear mixed effects model results for practice patterns and patient outcomes in intervention sites compared with control sites from baseline to follow-up

\begin{tabular}{lcr} 
Variable & OR $(95 \% \mathrm{Cl})$ & p value \\
\hline ABG measured & $9.8(2.1-44.9)$ & 0.006 \\
Salbutamol by MDI & $28.3(2.9-274.9)$ & 0.013 \\
Ipratropium bromide by MDI & $60.2(5.6-653.0)$ & 0.006 \\
Follow-up with or new referral & $14.4(5.9-34.9)$ & $<0.001$ \\
to an asthma specialist or & & \\
specialized asthma service & $3.9(1.8-8.4)$ & $<0.001$ \\
Recollection of teaching in & & \\
the ED & & \\
ABG = arterial blood gases; $\mathrm{Cl}=$ confidence interval; ED = emergency department; \\
MDI = metered-dose inhaler; OR = odds ratio.
\end{tabular}

Table 8. Generalized linear mixed effects model results for management practices and outcomes in patients who were on the asthma care pathway versus those who were not on the asthma care pathway at intervention sites at follow-up

\begin{tabular}{lcc} 
Variable & OR $(95 \% \mathrm{Cl})$ & $p$ value \\
\hline $\begin{array}{l}\text { PEFR documentation } \\
\begin{array}{l}\text { Systemic steroid } \\
\text { administration in the ED }\end{array}\end{array}$ & $3.9(4.4-14.2)$ & $<0.001$ \\
$\begin{array}{l}\text { Systemic steroid } \\
\text { administration on discharge }\end{array}$ & $2.6(1.5-5.3)$ & $<0.001$ \\
RT consultation in the ED & $17.5(5.4-56.3)$ & $<0.001$ \\
$\begin{array}{l}\text { Documentation of inhaler } \\
\text { teaching in the ED }\end{array}$ & $4.5(2.2-9.5)$ & $<0.001$ \\
$\begin{array}{l}\text { Cl = confidence interval; ED = emergency department; OR = odds ratio; PEFR = peak } \\
\text { expiratory flow rate; RT = respiratory therapist. }\end{array}$ &
\end{tabular}


the literature on the appropriateness and efficacy of patient education in the ED setting. ${ }^{25,26}$ Subsequent research should aim to determine the impact of educational efforts on ED workload and whether such initiatives leads to improved long-term outcomes.

Relapse rates are used in Ontario as benchmarks of ED care for asthma. ${ }^{27}$ In our study, the observed difference in relapse rates of $2 \%-5 \%$ favouring the intervention group was not statistically significant. However, this difference is consistent with a much larger study of 152 Ontario hospitals that found statistically significant absolute differences in pediatric repeat ED visit rates of $1.5 \%$ between hospitals with and without preprinted order sets. ${ }^{15}$ If the same is true of adult asthma preprinted orders, and since fewer than $40 \%$ of Ontario hospitals recently reported more than $75 \%$ of patients with asthma or COPD being cared for using standard protocols, ${ }^{26}$ then tremendous potential exists for improvement in relapse rates if barriers to uptake can be overcome.

\section{CONCLUSION}

Adoption of a standardized ED adult ACP is highly variable. Despite modest uptake, which averaged 26\%, a rigorous ITT analysis demonstrated beneficial changes in specific aspects of asthma care delivery, notably referrals and recollection of teaching done during the ED visit, without substantially prolonging ED length of stay. These changes may lead to improvements in outcomes, such as reduced relapse rates, which this study was not designed or powered to detect. Although selection bias may have existed, adherence to certain ED management strategies, such as increased documentation of PEFR, the use of systemic steroids in the ED and on discharge, and involvement of RTs (where available) in ED care appears improved in patients managed on an ACP. Provincial and national implementation strategies that address barriers to clinical pathway adoption are warranted and have the potential to improve adherence to guidelines and outcomes for asthma patients.

Acknowledgements: We thank site investigators Dr. Chris Bonnar, Dr. Max Buxton, Dr. Kenneth R. Chapman, Dr. Michael de la Roche, Dr. Varghese Koshy, Dr. Sean Moore, Dr. Marcus Newton, Dr. Nigel A.M. Paterson, and Dr. Malcolm R. Sears and site coordinators Alex Belanger, Orit Fruchtman, Irene Bonnar, Joanne Duncan, Brenda Fraser, Jennifer Clement, Maureen Magill, Laura Culligan, Zophie Roberts, Sally Gutoskie, and Amanda Windatt for their collaboration.
We also thank members of the project's Steering Committee (Dr. Lisa Cicutto, Sudha Kutty, Raj Bhanot, Nancy Garvey, Dr. Brian Rowe, Dr. Malcolm R. Sears, Libby Groff and Dr. Paul Hoogeveen), the Expert Content Working Group (Raj Bhanot, Dr. Sean Moore, Debbie Coutts, Jessica Meleskie, Dr. Gary Smith, Connie Sivyer, Sharon Ramagnano, Andrea White Markham, Dale Mackey, and Lawrence Jackson) and Ms. Yingua $\mathrm{Su}$ of the Kingston General Hospital Clinical Research Centre for assistance with data analysis.

Competing interests: None declared.

Funding: This study was funded by the Ontario Hospital Association and the Ontario Ministry of Health and Long-Term Care's Asthma Plan of Action.

\section{REFERENCES}

1. Public Health Agency of Canada. Life and breath: respiratory disease in Canada, 2007. Ottawa (ON): Public Health Agency of Canada; 2007. Available: www.phac-aspc.gc.ca/publicat /2007/lbrdc-vsmrc/index-eng.php (accessed 2009 Mar 16).

2. Asthma in Canada: a landmark survey. Mississauga (ON): Glaxo Wellcome Inc.; 2000. Available: http://asthmaeconomics .ca/pdf/GlaxoSmithKline.pdf (accessed 2009 Mar 16).

3. Canadian Institute for Health Information, Canadian Lung Association, Health Canada, Statistics Canada. Respiratory disease in Canada. Ottawa (ON): Health Canada; 2001.

4. To T, Dick PT, Feldman W, et al. Hospitalization for childhood asthma. Pediatric health service utilization. In: Goel V, Williams JI, Anderson GM, et al. Eds. Ottawa: the ICES practice atlas. 2nd ed. Ottawa (ON): Canadian Medical Association; 1996. p. 307-8.

5. Lajoie P, Laberge A, Lebel G, et al. Cartography of emergency department visits for asthma-targeting high-morbidity populations. Can Respir 7 2004;11:427-33.

6. Lougheed MD, Garvey N, Chapman KR, et al. The Ontario Asthma Regional Variation Study: emergency department visit rates and the relation to hospitalization rates. Chest 2006;129:909-17.

7. Krym VF, Crawford B, MacDonald RD. Compliance with guidelines for emergency management of asthma in adults: experience at a tertiary care teaching hospital. CJEM 2004;6:321-6.

8. Rowe BH, Bota GW, Clark S, et al. Comparison of Canadian versus American emergency department visits for acute asthma. Can Respir 7 2007;14:331-7.

9. Lougheed MD, Garvey N, Chapman KR, et al. Variations and gaps in management of acute asthma in Ontario emergency departments. Chest 2009;135:724-36.

10. Davis DA, Taylor-Vaisey A. Translating guidelines into practice. A systematic review of theoretic concepts, practical 
experience and research evidence in the adoption of clinical practice guidelines. CMAJ 1997;157:408-16.

11. Boulet L, Becker A, Bowie D, et al. Implementing practice guidelines: a workshop on guidelines dissemination and implementation with a focus on asthma and COPD. Can Respir J 2006;Mar(13 Suppl):A:5-47.

12. Mackey D, Myles M, Spooner CH, et al. Changing the process of care and practice in acute asthma in the emergency department: experience with an asthma care map in a regional hospital. CJEM 2007;9:353-65.

13. Dalcin Pde T, da Rocha PM, Franciscatto E, et al. Effect of clinical pathways on the management of acute asthma in the emergency department: five years of evaluation. I Asthma 2007;44:273-9.

14. Norton SP, Pusic MV, Taha F, et al. Effect of a clinical pathway on the hospitalisation rates of children with asthma: a prospective study. Arch Dis Child 2007;92:60-6.

15. Guttmann A, Zagorski B, Austin PC, et al. Effectiveness of emergency department asthma management strategies on return visits in children: a population-based study. Pediatrics 2007;120:e1402-10.

16. Garvey N, Lougheed MD. Asthma in Ontario: Ontario's asthma plan of action. In: Boulet L, Becker A, Bowie D, et al. Implementing practice guidelines: a workshop on guidelines dissemination and implementation with a focus on asthma and COPD. Can Respir 72006;13(Suppl A):32A-4A.

17. Beveridge RC, Grunfeld AF, Hodder RV, et al. Guidelines for the emergency management of asthma in adults. CMAJ 1996;155:25-37.

18. Boulet L-P, Becker A, Berube D, et al. Canadian asthma consensus report, 1999. CMAJ 1999;161(Suppl):S1-62.

19. Boulet L-P, Berube D, Cockcroft DW, et al. Asthma Guidelines Update 2001. Can Respir 7 2001;8:3A-27A.
20. Registered Nurses Association of Ontario. Tookit: implementation of clinical practice guidelines. Toronto (ON): The Association; 2002.

21. Benjamini Y, Hochberg Y. Controlling the rate of false discovery: a practical and powerful approach to multiple testing. Journal of the Royal Statistical Society 1995;57:289-300.

22. Emond SD, Woodruff PG, Lee EY, et al. Effect of an emergency department asthma program on acute asthma care. Ann Emerg Med 1999;34:321-5.

23. Bailey R, Weingarten S, Lewis $M$, et al. Impact of clinical pathways and practice guidelines on the management of acute exacerbations of bronchial asthma. Chest 1998;113:28-33.

24. Olajos-Clow J, Szpiro KA, Minard J, et al. Emergency department adult asthma care pathway: health care providers' perceived utility and barriers to implementation. Advanced Emergency Nursing Journal 2009;31:36-45.

25. Szpiro K, Harrison MB, VanDenKerkof EG, et al. Patient education in the emergency department: a systematic review of interventions and outcomes. Advanced Emergency Nursing Journal 2008;30:34-49.

26. Szpiro K, Harrison MB, VandenKerkof EG, et al. Asthma education in an emergency department and an asthma education centre: a feasibility study. Advanced Emergency Nursing Journal 2009;31:65-77.

27. Canadian Institute for Health Information, Government of Ontario, Ontario Hospital Association, Hospital Report Research Collaborative. The hospital report 2007: emergency department care. 6th ed. Ottawa (ON): Canadian Institute for Health Information; 2007.

Correspondence to: Dr. M. Diane Lougheed, 102 Stuart St., Division of Respirology, Department of Medicine, Queen's University, Kingston ON K7L 2V6; mdl@post.queensu.ca 